\title{
Evaluation of the efficacy of prolonged administration of azithromycin in a murine model of chronic toxoplasmosis
}

\author{
Jean-Luc Dumas ${ }^{a}$, Robert Chang ${ }^{a}$, Bernadette Mermillod ${ }^{b}$, Pierre François Piguet ${ }^{c}$, \\ Raymonde Comte ${ }^{a}$ and Jean-Claude Pechère ${ }^{a, \star}$ \\ ${ }^{a}$ Department of Genetics and Microbiology, Centre Médical Universitaire, ${ }^{b}$ Informatic \\ Center, Hôpital Cantonal Universitaire and 'Department of Pathology, Centre Médical \\ Universitaire, Geneva, Switzerland
}

\begin{abstract}
The efficacy of prolonged administration of azithromycin was evaluated in a murine model of lethal chronic toxoplasmosis. Mice were challenged intraperitoneally with cysts of a moderately virulent strain of Toxoplasma gondii, observed for 4 weeks and then allocated to the treatment or control group. All 26 animals given azithromycin $100 \mathrm{mg} / \mathrm{kg} /$ day for 100 days were protected compared with 19 of 25 control animals which died $(P<0.001)$. Nineteen of the 20 mice in the treatment group survived for an additional month while receiving the same azithromycin regimen but viable cysts were identified in the brain tissue of these animals when they were killed. Although there was no significant difference between the groups in terms of the number of cysts in the brain, the administration of azithromycin was associated with a reduction in brain inflammation. The concentrations of azithromycin in the brains of five animals ranged from 0.7 to $2.3 \mu \mathrm{g} / \mathrm{g}$; there was no evidence of accumulation even after 100 doses. Azithromycin merits further evaluation as primary or secondary prophylaxis against toxoplasma encephalitis in individuals at risk of developing this complication.
\end{abstract}

\section{Introduction}

Toxoplasma gondii is the most common cause of intracerebral mass lesions in patients with the acquired immunodeficiency syndrome (AIDS). Depending on the prevalence of latent toxoplasma infection in a given population, symptomatic toxoplasmosis of the central nervous system is diagnosed in $3-40 \%$ of AIDS patients (Levy, Bredesen \& Rosenblum, 1985; Luft \& Remington, 1988). The effective treatment of this infection is complicated by frequent intolerance to conventional antimicrobial agents and the high risk of relapse when therapy is discontinued (Leport et al., 1986, 1988; Haverkos, 1987; Wanke et al., 1987; Porter \& Sande, 1992). Strategies to prevent cerebral toxoplasmosis in AIDS patients with asymptomatic infection have therefore assumed increasing importance, bearing in mind that therapy directed against growing tachyzoites in symptomatic patients differs from prophylaxis in asymptomatic patients, the aim of which is to prevent cyst rupture and the consequence thereof.

While the efficacy of the macrolides as treatment for AIDS patients with toxoplasma encephalitis has been disappointing to date, it should not be assumed that these agents

\footnotetext{
* Correspondence to: Professor Jean-Claude Pechère, Department of Genetics and Microbiology, Centre Médical Universitaire, 9 Avenue de Champel, CH-1211 Geneva 4, Switzerland.
} 
would not be effective as prophylaxis, a possibility which has been suggested in a recent preliminary report (Durant et al., 1992). As this potential has not been adequately investigated, the present study was undertaken to assess the ability of the prolonged administration of azithromycin to prevent asymptomatic infection from progressing to encephalitis in a murine model of toxoplasmosis.

\section{Materials and methods}

\section{Antibiotic}

Azithromycin dihydrate was provided in powder form by Pfizer Central Research Division (Groton, CT, USA). It was mixed with saccharose $(0.35 \mathrm{mg} / \mathrm{dose})$, dissolved in ethanol ( $10 \mathrm{~mL} / \mathrm{g}$ of compound) and added to $4 \mathrm{~mL}$ of drinking water; the $\mathrm{pH}$ was adjusted to 7.2 with $0.1 \mathrm{M} \mathrm{NaOH}$.

\section{Toxoplasma strain}

The moderately virulent $T$. gondii strain PRU, which was originally isolated from an AIDS patient with cerebral toxoplasmosis, was provided by Professor Pestre-Alexandre (Limoges, France) and was maintained by serial intracerebral passage in mice. Cysts were obtained from the brains of mice infected 4 months previously. Brain tissue was ground through a 22-gauge needle $(0.7 \mathrm{~mm}$ in diameter) and diluted in phosphatebuffered saline (PBS) before inoculation.

\section{Animal model}

Infection was initiated by the inoculation of nine cysts suspended in $0.5 \mathrm{~mL}$ of PBS into the peritoneal cavities of $\mathrm{C} 57 \mathrm{BL} / 6 \mathrm{~J}(\mathrm{H}-2 \mathrm{~b})$ mice. Previous studies in our laboratory demonstrated that this invariably leads to fatal chronic toxoplasmosis in untreated animals, with death occurring in $80 \%$ of cases between 11 and 24 weeks after challenge.

\section{Therapeutic protocol}

Following inoculation, the mice were observed for 4 weeks. In order to prevent the development of acute toxoplasmosis, sulphadiazine $100 \mathrm{mg} / \mathrm{kg} /$ day was added to the drinking water of all mice from day 5 for 7 days. On day 30 , the animals were randomly allocated to the treatment or control group. The treatment group $(n=26)$ received azithromycin $100 \mathrm{mg} / \mathrm{kg} /$ day in drinking water for 130 days. The control group $(n=25)$ was maintained under the same conditions as the treatment group, except that the mice did not receive azithromycin.

The mortality attributed to toxoplasmosis was assessed after 100 days of treatment i.e. on day 131. Animals were examined daily and where death occurred during the day, a post-mortem examination was performed immediately and the number of cysts in the brain was determined as soon as possible after death. In the final stages of the disease, neurological signs were often apparent and euthanasia was practised, when appropriate, in accordance with the highest standards of animal experimentation. On day 131, six control and six treated mice were randomly selected and killed by the administration of a lethal dose of sodium thiopental; the brains of three animals in each group were assessed in order to determine the number of cysts present and the brain, 
spleen, liver and lungs of the remaining three were processed for histological examination. On day 161 , nine additional mice in each group were killed. Five were used to determine the concentration of azithromycin in brain tissue, while the brains of the other four were divided, one-half being used for the enumeration of cysts and the other half for histological examination. On day 205, the remaining ten mice were killed and samples of brain were inoculated into new mice in order to assess microbiological cure (see below).

\section{Determination of microbiological cure}

For each of the ten mice in the two groups which survived to day 205 , the brain was removed, ground with PBS through a 22-gauge needle and inoculated intraperitoneally into two new mice in order to assess the infectivity of the cysts. The inoculated animals were observed for the next 30 days. Mice which died during this period underwent postmortem examinations for evidence of toxoplasmosis; the surviving mice were killed and their brains examined for the presence of cysts.

\section{Antibiotic assay}

After macerating the brains on ice, azithromycin extraction was performed with ethanol. Ethanol extracts were evaporated at $8-12^{\circ} \mathrm{C}$ and the residue dissolved in $200 \mu \mathrm{L}$ of sodium buffer pH 8.0. The azithromycin concentrations in $100-\mu \mathrm{L}$ aliquots were determined by an agar diffusion method, described in the European Pharmacopoeia (Anonymous, 1992), with Difco medium ( $\mathrm{pH} \mathrm{8.0)}$ ) and Micrococcus luteus as the indicator organism. Standards were prepared by dissolving azithromycin in ethanol $(2 \mathrm{~g} / \mathrm{L})$ and making serial dilutions in sodium buffer $(\mathrm{pH} \mathrm{8.0})$. The zones of inhibition were measured after the plates had been incubated at $37^{\circ} \mathrm{C}$ for $24 \mathrm{~h}$; the threshold of sensitivity of the assay was $0.4 \mathrm{mg} / \mathrm{L}$. Antimicrobial activity in the brain of one untreated animal (control) and in those of three non-infected mice which had been given azithromycin $100 \mathrm{mg} / \mathrm{kg}$ for six consecutive days was also measured.

\section{Histological examination}

Immediately after death, the brain was removed from each animal, fixed in $10 \%$ buffered formalin and embedded in paraffin. Four coronal sections $(5 \mu \mathrm{m})$ were cut from the cerebral hemispheres and stained with haematoxylin and eosin. The degree of encephalitis was scored semi-quantitatively on an arbitrary scale of $0-3$ according to the following criteria: 3 , extensive inflammation and necrosis; 2 , extensive inflammation without visible necrosis; 1 , limited inflammation without visible necrosis; and 0 , normal tissue.

\section{Brain cyst counts}

Either the whole or one-half of each brain was suspended in PBS and passed ten times through a 20 -gauge $(0.9 \mathrm{~mm})$ needle and then a further ten times through a 22-gauge needle. The resulting tissue sample was centrifuged at $350 \mathrm{~g}$ for $10 \mathrm{~min}$ at $4^{\circ} \mathrm{C}$ and the total number of cysts in each brain was determined by microscopically screening successive $20-\mu \mathrm{L}$ aliquots until the entire pellet had been examined. 


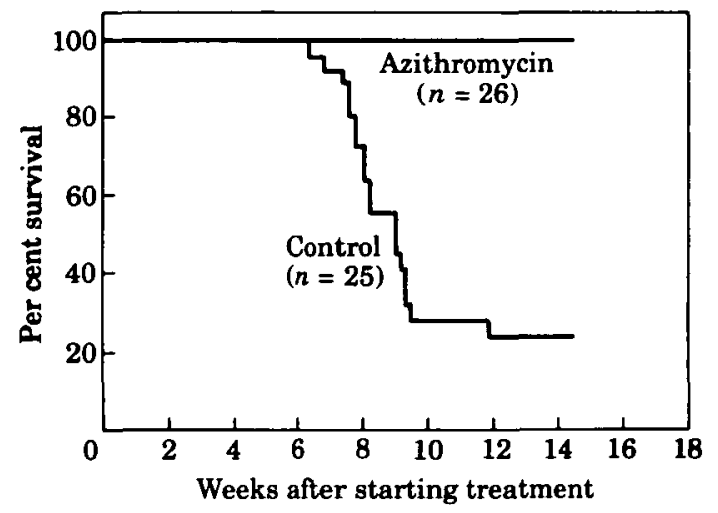

Figure. Cumulative survival in mice with chronic toxoplasmosis according to treatment group.

\section{Statistical analysis}

Comparison of the groups in terms of survival was based on Kaplan-Meier curves. Other results were compared with the Mantel-Cox log-rank test.

\section{Results}

\section{Control animals}

Nineteen of the $25(76 \%)$ untreated mice died during the 100 -day observation period (Figure) and the six surviving animals were killed on day 131 in order to assess the severity of infection. Of the ten post-mortem examinations which were performed, there was histological evidence of pneumonitis in all cases. The numbers of brain cysts ranged from 23 to 102 (mean 50-5) per brain (Table). Histological examination of three animals killed on day 131 showed inflammatory infiltrates in the lungs, spleen and liver; the encephalitis scores were 3 for two mice and 2 for one mouse (mean score $2 \cdot 7$ ). The brain lesions were characterized by a perivascular leucocyte infiltration (principally around intracerebral and meningeal blood vessels), the presence of microglial nodules and foci of necrosis.

Table. Numbers of cysts in the brains of control and azithromycin-treated mice

\begin{tabular}{lccc}
\hline Group & $\begin{array}{c}\text { No. of days after } \\
\text { inoculation }\end{array}$ & $\begin{array}{c}\text { No. of mice which } \\
\text { died or were } \\
\text { killed }\end{array}$ & $\begin{array}{c}\text { No. of brain cysts } \\
\text { per mouse }\end{array}$ \\
\hline Control & 81 & 1 & 31 \\
& 93 & 2 & 41,56 \\
& 94 & 1 & 42 \\
& 95 & 1 & 23 \\
Treated & 113 & 1 & 102 \\
& 130 & 1 & 52 \\
& 130 & 3 & $97,46,15$ \\
& 160 & 3 & $46,32,22$ \\
\hline
\end{tabular}




\section{Treated animals}

All 26 of the mice which received azithromycin survived and remained asymptomatic throughout the 100-day observation period; the difference between the two groups in terms of the incidence of mortality was therefore highly significant $(P<0.001)$. One mouse died from toxoplasmosis on day 141 i.e. after 110 days of therapy. The numbers of cysts in the brains of the seven mice killed on days 131 and 161 ranged from 22 to 96 per brain (Table); the mean of 40 cysts per brain was not significantly different from that for the untreated animals. Histological examination revealed inflammatory infiltration of the liver and lungs and the encephalitis scores were 0,1 and 1 for the three mice killed on day 131 and $0,0,1$ and 2 for the four mice killed on day 161 (mean score $0 \cdot 7)$.

Ten mice survived until day 205, 43 days after azithromycin administration was discontinued, and were used to assess eradication of the pathogen. Three of the 20 reinoculated mice died from acute toxoplasmosis within 30 days of the challenge and cysts were detected in the brains of the remaining 17 animals when they were killed.

The azithromycin concentrations in the brains of the five mice killed on day 161 were $0.7,0.8,0.9,1.1$ and $2.3 \mu \mathrm{g} / \mathrm{g}$; no antibiotic was detected in serum samples which were also obtained from these animals. There was no inhibitory activity in the brain tissue of the untreated mouse and the concentrations of azithromycin in the brains of the three non-infected mice were $1.6,1.9$ and $1.9 \mu \mathrm{g} / \mathrm{g}$.

\section{Discussion}

A murine model was chosen for the present study because of the resemblance to the disease in humans; in both cases, the untreated host remains asymptomatic for several months before developing a fatal infection which is characterized by neurological complications in the final stages. Azithromycin was selected because of the following properties: prolonged inhibition of the replication of intracellular tachyzoites (Chamberland, Kirst \& Current, 1991); in-vitro activity against cyst forms (Huskinson-Mark, Araujo \& Remington, 1991); high tissue specificity, with concentrations in the brain which are almost ten-fold higher than those in serum after oral dosing (Araujo, Shepard \& Remington, 1991); significant intracellular accumulation (Gladue et al., 1989); and potent activity in experimental murine toxoplasmosis (Araujo, Guptill \& Remington, 1988; Araujo et al., 1991; Derouin et al., 1992). A number of additional observations also suggested that azithromycin might be suitable in this context: a prolonged half-life (Girard et al., 1987), thereby allowing a simplified dosing schedule; good tolerability; lack of effect on zidovudine disposition in patients with AIDS (Chave et al., 1992); and potential activities against cryptosporidium and the Mycobacterium avium complex (Brown et al., 1993; Vargas et al., 1993). The $100-\mathrm{mg} / \mathrm{kg} /$ day dosage was used because it corresponds to that which is appropriate for man after size correction.

Prolonged administration of oral azithromycin $100 \mathrm{mg} / \mathrm{kg} /$ day reduced the incidence of mortality but failed to produce microbiological cure in this murine model of chronic toxoplasmosis. Efficacy in terms of reducing mortality was demonstrated although the dosage used was lower than that (c. $200 \mathrm{mg} / \mathrm{kg} /$ day) previously shown to be effective as therapy for the acute form of the disease (Araujo et al., 1991).

The experimental infection developed for use in the present study should be regarded as a model of chronic systemic toxoplasmosis involving several organs, most notably the liver, spleen, lungs and brain. Consequently, we were unable to identify the precise 
cause of death although, in all verified cases, severe interstitial lung infiltration and the histological features of encephalitis, consistent with fatal toxoplasmosis, were observed.

On day 131, the mean numbers of cysts in the brains of the six mice in the control and treatment groups were 50.5 and 40 respectively, values which were not significantly different. On the other hand, the administration of azithromycin was clearly associated with a reduction in cerebral inflammation. From these observations, we conclude that the protective effect of azithromycin was not due to the direct inhibition of brain cyst multiplication and that there is no correlation between the number of cysts in the brain and mortality. In a previous study involving a similar murine model, immunochemistry techniques were used to demonstrate the presence of toxoplasma antigen and extracystic toxoplasma tachyzoites within foci of acute brain inflammation, predominantly in relation to areas of perivascular leucocyte infiltration (Chang, Pechère \& Piguet, 1992). AIDS patients with cerebral toxoplasmosis present not only with brain cysts but also with extra- and intracellular tachyzoites (identified by immunochemistry), micronodules surrounding scattered cysts and free tachyzoites (Lang et al., 1989). On the basis of these findings, we suggest that the inflammatory reaction observed in the brain is a host response to the growth and spread of extracystic tachyzoites and, as shown in in-vitro studies (Chang \& Pechère, 1988; Chamberland et al., 1991), that azithromycin would be active against this form of the parasite. However, it is not clear whether the extracystic organisms associated with brain inflammation originated from local cyst disruption, from organs other than the brain, particularly the lungs (implying that the brain was infected secondarily via the systemic circulation), or from both of these sources. The second possibility is supported by the following evidence: brain cysts are not normally surrounded by inflammatory infiltrates, which tend to predominate in proximity to blood vessels; ruptured brain cysts are rarely seen on thin sections; and $T$. gondii can be demonstrated in the blood of immunosuppressed patients with severe toxoplasmosis.

The present study confirms the previously demonstrated antitoxoplasma activity of azithromycin. This agent has been shown to inhibit the replication of intracellular tachyzoites (Chang \& Pechère, 1988; Chamberland et al., 1991) and to produce an effect which is more prolonged than those of 23 other macrolides tested in parallel (Chamberland et al., 1991). It has also been shown to kill intracystic bradyzoites in vitro after 6 days of incubation (Huskinson-Mark et al., 1991). In mice infected with the highly virulent RH strain of $T$. gondii, azithromycin, administered in dosages of $200 \mathrm{mg} / \mathrm{kg} /$ day for 10 days, effectively prevented death from this organism and the same regimen also protected $80 \%$ of mice infected intracerebrally with the moderately virulent C56 strain (Araujo et al., 1988). In addition, azithromycin was superior to both roxithromycin and spiramycin in terms of protecting mice against death from acute toxoplasmosis (Araujo et al., 1991). This enhanced efficacy might be related to improved intrinsic antitoxoplasma activity or, alternatively, to higher tissue specificity.

In accord with earlier observations (Araujo et al., 1991), we detected azithromycin in the brains of all animals in concentrations which are known to be effective against susceptible organisms. However, in the present study, azithromycin, even when administered for periods of more than 3 months, failed to produce a microbiological cure, as demonstrated by the presence of cysts in the brain; its effect was confined to protecting mice against a fatal outcome.

Toxoplasma encephalitis is a severe, life-threatening infection, particularly in AIDS patients, and the identification of effective preventive measures must be a priority. Our 
observations suggest that azithromycin warrants further evaluation as primary or secondary prophylaxis in individuals at risk of developing this complication.

\section{References}

Anonymous. (1992). Titrage microbiologique des antibiotiques. In Pharmacopée Européene, 2nd edn. Maisonneuve, Sainte-Ruffine.

Araujo, F. G., Guptill, D. R. \& Remington, J. S. (1988). Azithromycin, a macrolide antibiotic with potent activity against Toxoplasma gondii. Antimicrobial Agents and Chemotherapy 32, 755-7.

Araujo, F. G., Shepard, R. M. \& Remington, J. S. (1991). In vivo activity of the macrolide antibiotics azithromycin, roxithromycin and spiramycin against Toxoplasma gondii. European Journal of Clinical Microbiology and Infectious Diseases 10, 519-24.

Brown, S. T., Edwards, F. F., Bernard, E. M., Tong, W. \& Armstrong, D. (1993). Azithromycin, rifabutin, and rifapentine for treatment and prophylaxis of Mycobacterium avium complex in rats treated with cyclosporine. Antimicrobial Agents and Chemotherapy 37, 398-402.

Chamberland, S., Kirst, H. A. \& Current, W. L. (1991). Comparative activity of macrolides against Toxoplasma gondii demonstrating utility of an in vitro microassay. Antimicrobial Agents and Chemotherapy 35, 903-9.

Chang, H. R. \& Pechère, J.-C. (1988). In vitro effects of four macrolides (roxithromycin, spiramycin, azithromycin [CP-62,993], and A-56268) on Toxoplasma gondii. Antimicrobial Agents and Chemotherapy 32, 524-9.

Chang, H. R., Pechère, J.-C. \& Piguet, P.-F. (1992). Role of tumor necrosis factor in chronic murine Toxoplasma gondii encephalitis. Immunology and Infectious Diseases 2, 61-8.

Chave, J.-P., Munafo, A., Chatton, J.-Y., Dayer, P., Glauser, M. P. \& Biollaz, J. (1992). Once-a-week azithromycin in AIDS patients: tolerability, kinetics, and effects on zidovudine disposition. Antimicrobial Agents and Chemotherapy 36, 1013-8.

Derouin, F., Almadany, R., Chau, F., Rouveix, B. \& Pocidalo, J.-J. (1992). Synergistic activity of azithromycin and pyrimethamine or sulfadiazine in acute experimental toxoplasmosis. Antimicrobial Agents and Chemotherapy 36, 997-1001.

Durant, J., Hazime, F., Bernard, E., Carles, M., Pechère, J.-C. \& Dellamonica, P. (1992). An open randomized study of roxithromycin efficacy and tolerance in the primary prevention of pneumocystosis and cerebral toxoplasmosis in 52 HIV-positive patients. In Program and Abstracts of the Thirty-Second Interscience Conference on Antimicrobial Agents and Chemotherapy, Anaheim, California, 1992. Abstract 1216, p. 313. American Society for Microbiology, Washington, DC.

Girard, A. E., Girard, D., English, A. R., Gootz, T. D., Cimochowski, C. R., Faiella, J. A. et al. (1987). Pharmacokinetic and in vivo studies with azithromycin (CP-62,993), a new macrolide with an extended half-life and excellent tissue distribution. Antimicrobial Agents and Chemotherapy 31, 1948-54.

Gladue, R. P., Bright, G. M., Isaacson, R. E. \& Newborg, M. F. (1989). In vitro and in vivo uptake of azithromycin (CP-62,993) by phagocytic cells: possible mechanism of delivery and release at sites of infection. Antimicrobial Agents and Chemotherapy 33, 277-82.

Haverkos, H. W. (1987). Assessment of therapy for toxoplasma encephalitis. American Journal of Medicine 82, 907-14.

Huskinson-Mark, J., Araujo, F. G. \& Remington, J. S. (1991). Evaluation of the effect of drugs on the cyst form of Toxoplasma gondii. Journal of Infectious Diseases 164, 170-7.

Lang, W., Miklossy, J., Deruaz, J. P., Pizzolato, G. P., Probst, A., Schaffner, T. et al. (1989). Neuropathology of the acquired immune deficiency syndrome (AIDS): a report of 135 consecutive autopsy cases from Switzerland. Acta Neuropathologica Berlin 77, 379-90.

Leport, C., Raffi, F., Matheron, S., Katlama, C., Regnier, B., Saimot, A. G. et al. (1988). Treatment of central nervous system toxoplasmosis with pyrimethamine/sulfadiazine combination in 35 patients with the acquired immunodeficiency syndrome: efficacy of longterm continuous therapy. American Journal of Medicine 84, 94-100.

Leport, C., Vilde, J.-L., Katlama, C., Regnier, B., Matherson, S. \& Saimot, A. G. (1986). Failure of spiramycin to prevent neurotoxoplasmosis in immunosuppressed patients. Journal of the American Medical Association 255, 2290. 
Levy, R. M., Bredesen, D. E. \& Rosenblum, M. L. (1985). Neurological manifestations of the acquired immunodeficiency syndrome (AIDS): experience at UCSF and review of the literature. Journal of Neurosurgery 62, 475-95.

Luft, B. J. \& Remington, J. S. (1988). AIDS commentary: toxoplasmic encephalitis. Journal of Infectious Diseases 157, 1-6.

Porter, S. B. \& Sande, M. A. (1992). Toxoplasmosis of the central nervous system in the acquired immunodeficiency syndrome. New England Journal of Medicine 327, 1643-8.

Vargas, S. L., Shenep, J. L., Flynn, P. M., Pui, C. H., Santana, V. M. \& Hughes, W. T. (1993). Azithromycin for treatment of severe Cryptosporidium diarrhea in two children with cancer. Journal of Pediatrics 123, 154-6.

Wanke, C., Tuazon, C. U., Kovacs, A., Dina, T., Davis, D. O., Barton, N. et al. (1987). Toxoplasma encephalitis in patients with acquired immune deficiency syndrome: diagnosis and response to therapy. American Journal of Tropical Medicine and Hygiene 36, 509-16.

(Received 23 July 1993; revised version accepted 10 March 1994) 